INORg. NUCL. CHEM. LetTers Vol. 8, pp. 45-50, 1972. Pergamon Pregs. Printed in Great Britain.

\title{
NICKEL (II) MONOTHIOCARBAMATES
}

J. Willemse

Department of Inorganic Chemistry, University of Nijmegen, Nijmegen, The Netherlands

(Rece ived 1 June 1971)

In addition to our work at dithiocarbamato complexes (1) we started some time ago in synthetizing monothiocarbainato complexes.

The publication of Krankovits et.al. (2) of the synthesis of nickel (II) bis(pyrrolidine monothiocarbamate)

[Ni(pyrrolmtc) 2$]$, prompts us to report our investigations of nickel (II) bis(di-n-propyl monothiocarbamate) $\left[\mathrm{Ni}\left(\mathrm{n}-\mathrm{pr}_{2} \mathrm{mtc}\right)_{2}\right]$.

This compound has a much better solubility in organic solvents than the pyrrolidine derivative, so purification by recrystallization is possible and spectroscopic and osmometric studies of solutions can be accomplished. Our results agree with those of Krankovits indicating a polymeric nature of the compounds, however a more detailed picture can now be given for the di-n-propyl compound.

\section{PREPARATION}

$\underline{\mathrm{Ni}(\mathrm{n}-\mathrm{pr}} 2 \underline{\mathrm{mtc}}_{2}: 0.15 \mathrm{~mole}$ di-n-propylamine in $200 \mathrm{ml}$ acetone and $0.15 \mathrm{~mole} \mathrm{KOH}$ in $10 \mathrm{ml}$ water were mixed and cooled to $5^{\circ} \mathrm{C}$. Cos gas was passed through this solution till saturation. 
The reaction mixture was dropped to a saturated aqueous solution of 0.075 mole nickelacetate. The precipitate was filtered and washed with acetone, a further purification was possible by dissolving the product in chloroform and reprecipitation with acetone yielding dark green-yellow crystals.

Analysis C: $44.34 \% ; \mathrm{H}: 7.41 \% ; \mathrm{N}: 7.39 \%$; $0: 8.58 \%$;

$\mathrm{S}: 16.67 \%$; Ni: 15.60\%. Calc. for $\mathrm{Ni}\left(\mathrm{OSCNC}_{6} \mathrm{H}_{14}\right)_{2}$ :

$\mathrm{C}: 44.34 \% ; \mathrm{H}: 7.44 \% ; \mathrm{N}: 7.39 \% ; 0: 8.44 \% ; \mathrm{S}: 16.91 \%$;

$\mathrm{Ni}: 15.48 \%$.

$\underline{\mathrm{Ni}\left(\mathrm{n}-\mathrm{pr}_{2} \mathrm{mtc}\right)} 2 \mathrm{py}_{2}$ : A bispyridine adduct cuuld be obtained by dissolving $\mathrm{Ni}\left(\mathrm{n}-\mathrm{pr}_{2} \mathrm{mtc}\right)_{2}$ in chloroform, addinte pyridine and precipitating the compound with ethanul. Analysis $0: 53.57 \% ; \mathrm{H}: 7.12 \% ; \mathrm{N}: 10.49 \%$. Calc. for $\mathrm{Ni}\left(\mathrm{OSCNC}_{6} \mathrm{H}_{14}\right)_{2}\left(\mathrm{C}_{5} \mathrm{H}_{5} \mathrm{~N}\right)_{2}: \mathrm{C}: 53.64 \% ; \mathrm{H}: 7.13 \% ; \mathrm{N}: 10.43 \%$.

\section{DISCUSSION}

In contrast with the observations of Krankovits for $\mathrm{Ni}\left(e t_{2}\right.$ mtc $_{2}$ our analysis and IR data clearly indicate that there is no water present in $\mathrm{Ni}\left(\mathrm{n}-\mathrm{pr}_{2}\right.$ (ntc $_{2}$. The Ni-S vibration frequency for Nickel bis(dialkyldithiocarbanate) is found at $387 \mathrm{~cm}^{-1}$ (3). The Ni-0 stretching frequency in nickel (II) acetylacetonate is found at $452 \mathrm{~cm}^{-1}$ (4). In the infrared spectra of nickel(II) bis(di-n-propylmonothiocarbamate) absorption bands are found at 385 and 450 $\mathrm{cm}^{-1}$ so the conclusion is drawn that the ligand is coordinated to the metal through sulphur as well as oxyeen. Table I gives a comparison between some frequencies found for our species and the various pyrrolidine compounds (2): 
Some infrared absorption frequencies, positions are siven in $\mathrm{cm}^{-1}$

\begin{tabular}{|c|c|c|c|c|}
\hline & $\mathrm{Ni}\left(n-\mathrm{pr}_{2} \mathrm{mtc}\right)_{2}$ & $\mathrm{Ni}\left(\mathrm{n}-\mathrm{pr} 2^{\mathrm{mtc}}\right)_{2} \mathrm{py}_{2}$ & $\mathrm{Ni}($ pyrrolmtc $) 2^{\mp}$ & $\mathrm{Ni}(\text { pyrrolmtc })_{2}$ dipyrrol \\
\hline$\nu c-0$ & 1545 & 1540 & 1610 & 1618 \\
\hline$\sqrt{C-N}$ & 1525 & 1520 & 1540 & 1500 \\
\hline$\nu \mathrm{C}-\mathrm{s}$ & 668 & 672 & 671 & 670 \\
\hline
\end{tabular}

*Data from Krankovits et. al. (2) 
We did not find any band in the $1600 \mathrm{~cm}^{-1}$ regio so we described the $1545 \mathrm{~cm}^{-1}$ band to the $0-0$ frequency which is appreciable lower than Krankovits et.al. found for the pyrrolidine monothiocarbamate. There is no explanation at hand for this large difference. The higher $\mathrm{C}-\mathrm{N}$ and $\mathrm{C}-\mathrm{S}$ frequencies as compared with $\mathrm{Ni}\left(\mathrm{n}-\mathrm{pr}_{2} \mathrm{dtc}_{2}\left(1505\right.\right.$ and $\left.616 \mathrm{~cm}^{-1}\right)$ indicate that the canonical forms $b$ and $c$ with double bond character of the $\mathrm{C}-\mathrm{N}$ and $\mathrm{C}-\mathrm{S}$ bond are more important than in the dithiocarbamate.<smiles>[R][N+]([R])[C@H]1O[SiH2][C@@H]1O</smiles>

a<smiles>[R]N=C([O-])[O-]</smiles>

b<smiles>[R][N+]([R])=[Se][O-]</smiles>

c

The data from the visible spectra of the compounds are given in table II. They show a good agreement and can be interpreted assuming pseudo-octahedral symmetry. The masnetic susceptibility of $\mathrm{Ni}\left(\mathrm{n}-\mathrm{pr}_{2} \mathrm{mtc}_{2}\right.$ was measured between 93 and $293^{\circ} \mathrm{K}$, the Curie-Weiss law was closely followed with a Weiss temperature of $5^{\circ} \mathrm{K}$ and a manetic moment of $3.31 \mathrm{BM}$, which is just in the ranse normally found for octahedral Ni(II) compounds. The bispyridine adduct showed a room temperature masnetic moment of 3.25 BM. Molecular weishts of $\mathrm{Ni}\left(\mathrm{n}-\mathrm{pr}_{2} \mathrm{mtc}_{2}\right.$ and $\mathrm{Ni}\left(\mathrm{n}-\mathrm{pr}_{2} 2^{\mathrm{ntc}}\right)_{2} \mathrm{py}_{2}$ were determined osmometrically in $\mathrm{CCl}_{4}$ solutions. 1900 and 520 were found respectively, which correspond to $\left[\mathrm{Ni}\left(\mathrm{n}-\mathrm{pr}_{2} \mathrm{mtc}\right)_{2}\right]_{5}$ (calc. mol. weight 1896) and a monomolecular 
Visible absorption spectra of some monothiocarbamato complexes

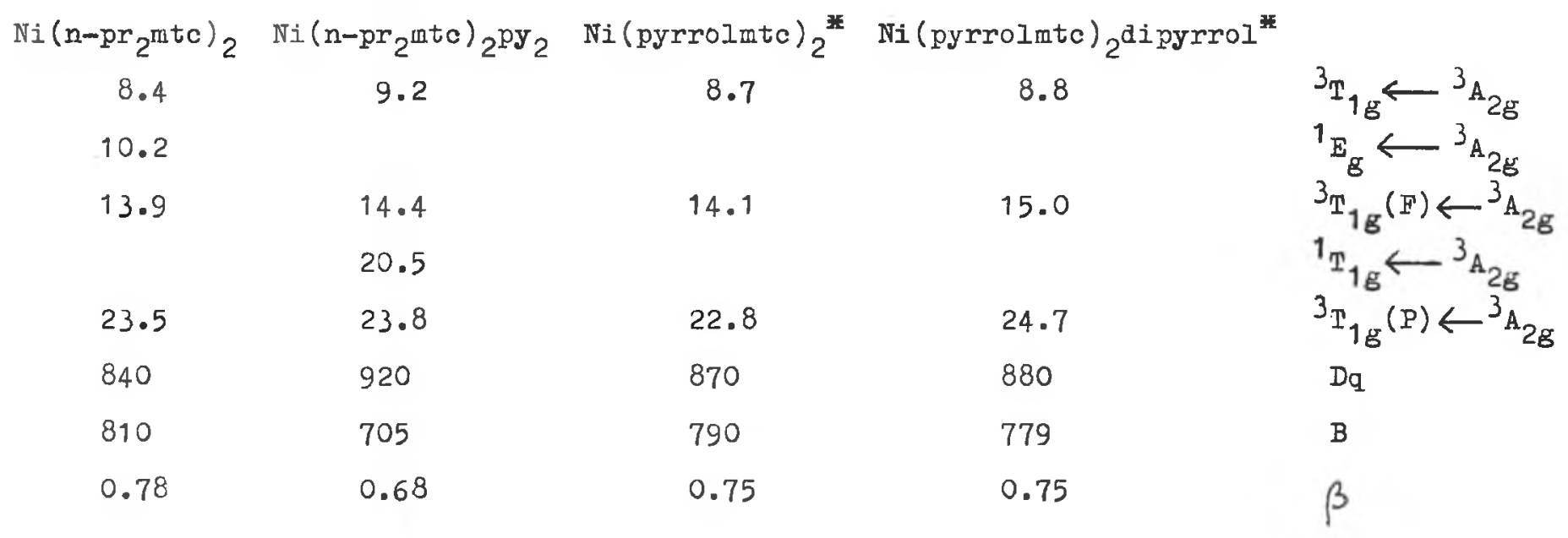

Transitions are given in $k \mathrm{~K}$. Dq is the ligand field parameter in $\mathrm{cm}^{-1}$. B is the Racah parameter in $\mathrm{cm}^{-1}$ and $\beta$ the nephelauxetic ratio calculated with $\mathrm{B}$ is $1041 \mathrm{~cm}^{-1}$ for the gaseous $\mathrm{Ni}^{2+}$ ion.

*Data from Krankovits et. al. (2). 
bispyridine adduct (calc.mol. weight 537). The mass spectrum of $\mathrm{Ni}\left(\mathrm{n}-\mathrm{pr}_{2} \mathrm{mtc}\right)_{2}$ showed the highest $\mathrm{m} / \mathrm{e}$ value at 758 corresponding with a dimer. As the IR and UV-Vis spectra of crystalline and $\mathrm{CCl}_{4}$ solutions of the compound were much alike, a similar polymer structure in both phases is suggested. Structural studies of the compound are in progress.

\section{ACKNOWLEDGEMENT}

The author wishes to thank Prof. J.J. Steggerda for his continued interest, Mr. E.H.M. Vroemen for his contribution in the experimental work and Mr. J. Diersmann for yerforming the analyses.

The investigations were supported in part by the Netherlands Foundation for Chemical Research (S.O.N.) with financial aid from the Netherlands Organisation for the Advancement of Pure Research.

\section{REFERENCES}

(1) H.C. Brinkhoff, J.A.Creis, J.J. Steggerda and J. Willemse, Rec.Trav. Whim. 88, 633 (1969).

(2) E.M. Krankovits, R.J. Magee and M.J. O'Connor, Inoró. Nucl. Chem. Letters 1, 541 (1971).

(3) H.C. Brinkhoff, Thesis, Nijmegen 1970.

(4) K. Nakamoto, Infrared Spectra of Inorganic and Coordination Compounds, p. 217. John Wiley \& Sons, Inc. New York, London (1963). 
INORG. NUCL. CHEM. LeTters Vol. 8, pp. 389-391, 1972. Pergamon Press. Printed in Great Britain.

NICKEL BIS(N, N DI-n-BUTPYLDITHIOCARBAMATO) IODIDE.

A NEW COMPOUND WITH NICKEL IN A FORMAL OXIDATION

STATE II.I

(Received 13 January 1972)

By J. Willemse, P.H.F.M. Føøwette, J.A. Cras

Department of Inorganic Chemistry

University of Ni jmegen, Ni jmegen, The Netherlands

\section{Introduction}

During the investigations on the oxldation of palladium and platinum bis $(N, N$ dialkyldithiocarbamate) wo found compounds with stoichiometry $M\left(R_{2} d t c\right)_{2} X_{2}\left(X=C l, B r\right.$ and $R_{2} d t c=N, N$ dialkyldithiocarbamato group $) 1$ 。 The platinum complexes could be synthetized at room temperature, whereas the palladiun compounds could only be obtained by lowering the temperature of the reaction mixture to $0^{\circ}$. Atiempts to prepare nickel complexes with the same stoichiometry failed until now. $N i(I V)\left(R_{2} d t c\right)_{3} x$ was obtained when the oxidation was carried out at room temperature, on cooling of a reaction mixture to $-30^{\circ}$ however, a new $\mathrm{Ni}$ (III) compound $-\mathrm{Ni}$ (III) (bu $\left.\mathrm{b}^{\mathrm{dtc}}\right)_{2}$ Iresulted.

\section{Experimental part}

To a solution of 1 mole $I_{2}$ in diethylether, cooled to $-30^{\circ}, 2$ moles of $\mathrm{Ni}\left(b_{2} \mathrm{dtc}\right)_{2}$ were added. The reaction mirture was stirred for several hours at $-30^{\circ}$ and $\mathrm{Ni}\left(\mathrm{bu}_{2} \mathrm{dtc}\right)_{2}$ slowly dissolved whereas a black precipitate appeared. After filtration the compound was washed with water and with cold diethylether and dried at room temperature 
Melting point : $88^{\circ}$ (decomposition)

Analyes : :

Found $\quad$ C C,36,41; H,6.10; N,4.71; S,21.58; I,21.57; Ni.9.96\%

Calc. for $\mathrm{NiC}_{18} \mathrm{H}_{36} \mathrm{~N}_{2} \mathrm{~S}_{4} \mathrm{~T}$ : C, $36.37 ; \mathrm{H}, 6.02 ; \mathrm{N}_{1} 4.80 ; \mathrm{S}, 21.60 ; \mathrm{I}, 21.35$;

Ni. $9.88 \%$

\section{Discussion}

Analytical data showed the stoichionetry to be $\mathrm{Ni}\left(\mathrm{bu}_{2} \mathrm{dtc}\right)_{2} \mathrm{I}$. Because of decomposition in solvents as chloroform and benzene no molecular woight determinations could be performed. UVV solution spectra yielded evidence that in chloroform the decomposition proceeded slowly to $\mathrm{Ni}\left(\mathrm{bu}_{2} \mathrm{dtc}\right)_{2}$ and iodine. In ethylalcohol $\mathrm{Ni}\left(\mathrm{bu}_{2} \mathrm{dtc}\right)_{2} \mathrm{I}$ solution disproportionated to $\mathrm{Ni}\left(b u_{2} d t c\right)_{3} I_{3}$ and $\mathrm{Ni}\left(b u_{2} d t c\right)_{2}$.

From infrared epectra recorded in CBI on a Perkin Elmer 257 epectrophotometer in the regio $4000-700 \mathrm{~cm}^{-1}$ the $\mathrm{C}-\mathrm{N}$ stretching frequency was found to increase with increasing formal oxidation number as expected $\left(\mathrm{Ni}\left(\mathrm{bu}_{2} \mathrm{dtc}\right)_{2}, 1502 \mathrm{~cm}^{-1}\right.$; $\left.\mathrm{Ni}\left(\mathrm{bu}_{2} \mathrm{dtc}\right)_{2} \mathrm{I}, 1518 \mathrm{~cm}^{-1} ; \mathrm{Ni}\left(\mathrm{bu}_{2} \mathrm{dtc}\right)_{3} \mathrm{I}_{3}{ }^{2,3)}, 1538 \mathrm{~cm}^{-1}\right)$. The spectrum in the regio $700-200 \mathrm{~cm}^{-1}$ recorded in CsI on a Hitachi EPI-L apparatus showed an absorption band at $377 \mathrm{~cm}^{-1}$ which we ascribed to one of the M-S stretching frequencies and at $275 \mathrm{~cm}^{-1}$ which could be due to a Ni-I stretching frequency.

Magnetic measurements on a Gouy balance showed that the Curie - Weiss law was followed in the range from 103 till $295^{\circ} \mathrm{K}$, with a Weiss temperature $\theta=-28^{\circ} \mathrm{K}$.

For $\mu_{\text {eff }}$ value of 1.33 was found. This value ruled out either a $d^{7}$ tetrahedral or a octahedral high spin configuration but is low for a five coordination or an octahedral low spin where one unpaired electron and thus $\mu_{\text {eff }}$ of .1 .73 is expected. 
Probably a remainder of antiferromagnetic coupling is present. This is supported by the negative value of $\theta$ indicating antiferromagnetion at very low temperatures.

An esr spectrum of a powdered sample revealed three absorption lines from which the three principal g-values could be calculated to be $2.260,2.215$ and 2.027 rqspectively. Because the values $g_{1}$ and $g_{2}$ are nearly the same, there is almost and axial symmetry around the direction of $g_{3^{\circ}}$. These data could be ascribed to a square pyramidal coordination of the Ni atom in which we should expect $g_{1}=g_{2} \neq g_{3}$.

\section{Acknowledpment}

Thanks are due to Mr. E.W.J.M. van der Drift for the recording of the esr spectra and to Professor J.J. Steggerda for his interest in the work.

\section{References}

1) J.A. Cras, J. Willemse, to be published.

2) H.C. Brinkhoff, Rec. Trav. Chim. 20 (1971) 377.

3) H.C. Brinkhoff, Thesis, Nijmegen 1970. 
